\title{
Disgenesia gonadal con cromatina positiva
}

Dr. Manuel Aspilłga H.1 ; Dra. Isabel Avendaño B. 2 ;

T.M. María Isabel Aguirre O. ${ }^{3}:$ T.M. Cecilia Labraña T.4

\section{Gonadal dysgenesis with positive chromatine}

Two cases of chromatine positive, gonadal dysgenesis are described, both mosaicism, one with Xq isochromosome and the other with ring X chromosome. Comparisons among their clinical findings with Turner's syndrome, and possible differences in evolution and prognosis are emphasized.

(Key words: Chromatine positive, gonadal dysgencsis, $\mathrm{Xq}$ isochromosome, Xring chromosome, mosaicism).

En las células somáticas, en una etapa precoz de la embriogénesis se inactiva al azar parte o todo un cromosoma $X$ (paterno o materno). De acuerdo a la teoría de Lyon ${ }^{1}$, ello sería necesario para evitar repeticiones o duplicaciones de genes. Mediante los modelos ${ }^{2,3}$ que describen la evolución filogenética de los gonosomas, podríamos explicar los sintomas de las aberraciones del cromosoma $X$. El gonosoma patológico es el que generalmente se inactiva, formando una cromatina de Barr variable en tamaño de acuerdo a la anomalía estructural.

Nos referimos a dos casos de esas alteraciones con cromatina positiva: uno con isocromosoma $\mathrm{Xq}$, que no es infrecuente, y otro con un $\mathrm{X}$ en anillo lo que constituye una excepción.

\section{Casos clínicos}

1: niña, 14 afros y 7 meses de edad que consultó por talla baja, ausencia de desarrollo puberal y enuresis. Su madre tenía 35 años, su talla era $1,56 \mathrm{~m}$ y era portadora de insuficiencia mitral y escoliosis. Su padre, de 37 años media $1,62 \mathrm{~m}$ de alto, sano. Una hermana de 11 años epiléptica. La propósito fue el primer hijo, nació antes del término pesando $2.600 \mathrm{~g} \mathrm{y}$ sufrió asfixia. En el primer año de vida tuvo infecciones

1. Profesor de Pediatría. Unjversidad de Chile. Unidad de genética, Hospital Luis Calvo Mackenna.

2. Médico Servicio de Salud Metropolitano Oriente, Unidad de genética, Hospital Luis Cako Mackenna.

3. Tecrólogo Médico, Universidad de Chile, Hospital Luis Calvo Mackenna.

4. Tecnólogo Médico. Servicio Salud Metropolitano Oriente, Hospital Luis Cávo Mackenna. urinarias. Actualmente estudia primer año medio. Mide $1,34 \mathrm{~m}$ de talla, pesa $33,5 \mathrm{~kg}$, tiene lunares faciales, dientes mal implantados, pelo nucal bajo; tórax ancho, mamilas separadas, sin desarrollo glandular (Fig. 1); vello axilar inexistente; cúbito valgo, ufias hiperconvexas, soplo cardíaco, sistólico 2/6; presión arterial de

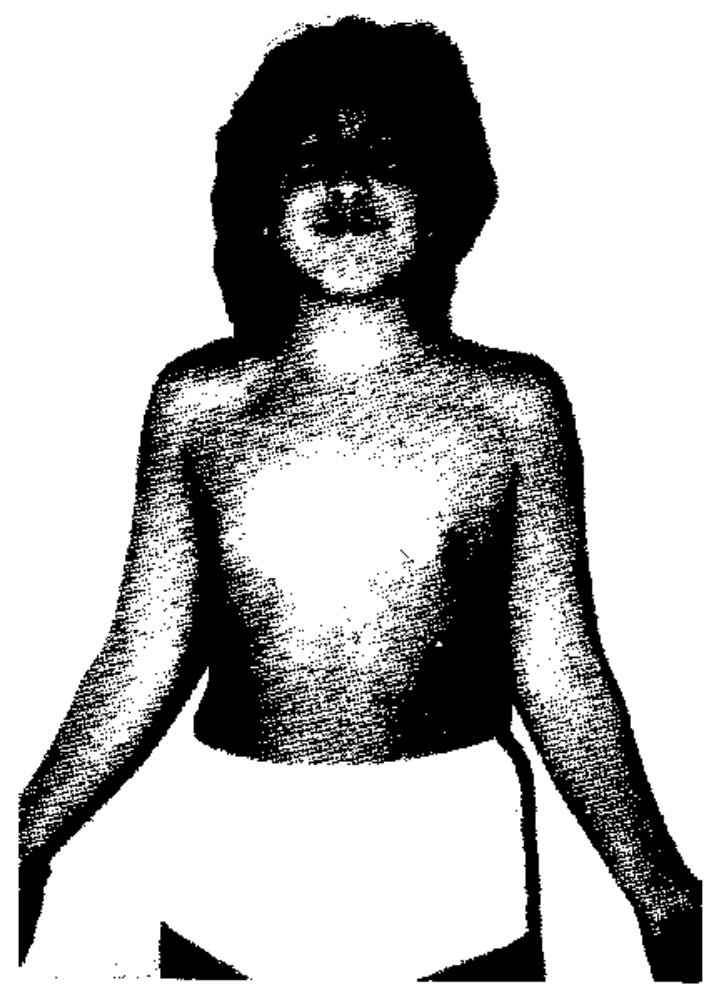

Figura 1. Paciente 1: aspecto físico, destacando tórax ancho, mamiłas separadas, cúbito valgo, y lunares faciales. 
$110 / 90 \mathrm{~mm}$ de $\mathrm{Hg}$. Nódulo ulerino palpable de 1 x $0.5 \mathrm{~cm}$, anexos no palpables; vello fino en el promontorio pubiano y borde de labios mayores: ninfas sólo en el terio superior: himen delgado y clitoris normal. Ecografia ginecológica: utero de $1,4 \mathrm{~cm}$ de largo: a izquierda cintilla de $0,8 \mathrm{~cm} \mathrm{en}$ la zona gonadal, no se recunoce ovarios. Urocultivos negativos. Edad ósea 12 años. Piclografía de climinación: rotación renal inconpleta a izquierda; resto normal. Cistometria: vejiga hiperrefléxica con asincronia de esfinter interno. Tono anal positivo. Reflejo anal positivo. Uretrocistografía normal. Cromatina $X$ positiva en $26 \%$, con discreto aumento de tamaño de los corpúsculos. Cariograma de lintocitos de sangre periférica: mosaico $45, \mathrm{Xo} ; 46, \mathrm{X}$ iso $\mathrm{Xq} / 47, \mathrm{X}$ iso $\mathrm{Xq}$ isoXq/48. X isoXq isoXq isoXq ( $\mathrm{Fig}_{\mathrm{ig}}$ ) ), en proporciones dc $7,68,22$ y $3 \%$ respectivamente. Niveles de F.S.H. $39 \mathrm{~m}$ Ul $\times$ ml y L.H. $5 \mathrm{~m}$ Ul $x$ $\mathrm{ml}$. Se le indicó tratamietito de sustitución con estrógenos equinos en dosis de $0,6 \mathrm{mg}$ diarios. Siete meses después su talla cra de 1,40 m, las mamas tenian un desarrolio de tapa III de Tanner; el vello axilar habia aparecido y el pubiano aumentado, el útero media $1,3 \mathrm{~cm}$ en la palpacióni; se aumentó la dosis de estrógeno a $1.25 \mathrm{mg}$ diarios onbteniéndose un flujo menstrual adecuado.

2: Niña, procedente de Tálca, consultó por clitorimegalia. Padre 43 años, madre de 35 años, hermana de 9 años, sanos. Es la primera hija. En el embarazo la madre tuvo hipertensión. Nació a los 7 meses de gestación en el hospital de Talca, pesaba $1.090 \mathrm{~g}$, su talla era "muy pequeña"; estuvo 7 días en incubadora. Su desarrollo psico. motor al parecer fue normal. La familia le notó el clítoris muy aumentado de tamaño, por lo que la trajo a consultar. Un cariograma de linfocitos hecho en otro hospital, a los 3 años de edad. reveló $90 \%$ de mitosis $45, \mathrm{XO}$ y $10 \% 46, \mathrm{XX}$. En esa época sufrió dos infecciones urinarias. Su rendimiento escolar ha sido deficiente, a los 12 años y 8 meses cursaba cuarto año básico con dificultades.

Medía $1,20 \mathrm{~m}$ de talla, pesaba $25,5 \mathrm{~kg}$. Su cuello era ligeramente alado; tórax ancho, distancia intermamilar $18 \mathrm{~cm}$, aumento de volumen mamario correspondiente a rejido celular subcutáneo. No habia alteraciones evidentes en cara, cráneo, aparato cardiovascular, sistema respiratorio ni abdomen. En las extremidades superiores tenia cúbito valgo, acortamiento del cuarto $y$ quinto huesos metacarpianos, uñas hiperconvexas casi sin lúnula, articulaciones laxas; los trirradios de los dermatoglifos estaban desplazados hacia el lado cubital en la mano derecha y en los dedos habian 10 presillas cubitales. En las extremidades

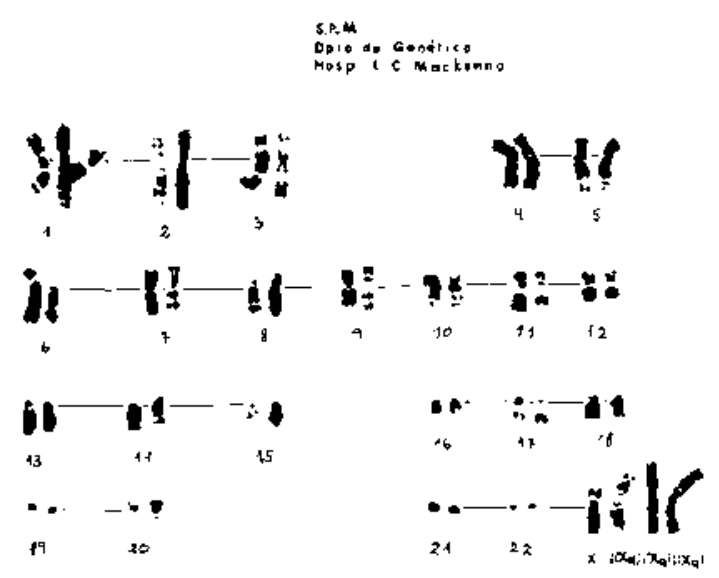

Figura 2. Paciente 1: Cariograma: Descripcien en tel texio.

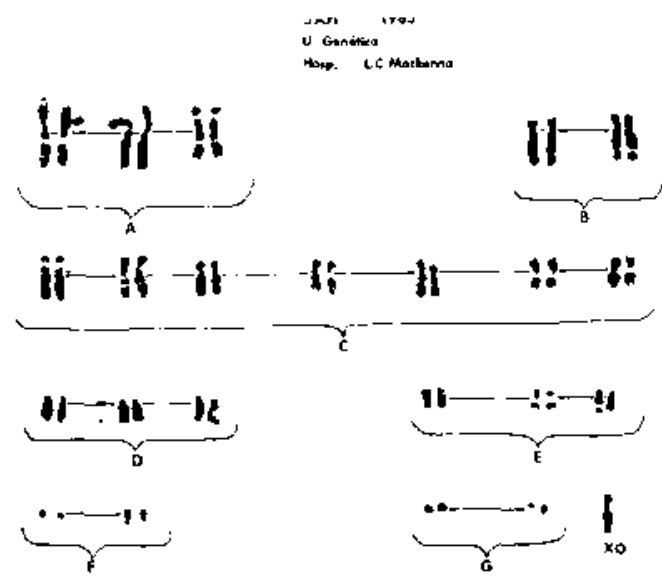

Figura 3: Paciente 2, Cariograma: Descripción en el texto.

inferiores habia buen desarrollo muscular y el quinto metatarsiano era corto. Sus labios mayores y menores eran normales, vagina pequeña. himen permeable, clítoris de $1 \mathrm{~cm}$ de largo y $0,5 \mathrm{~cm}$ de diámetro con capuchón redundante. En la pielografía de eliminación se observó dilatación extramural de las pélvices con cálices de aspecto normal y buen vaciamiento en 5 minutos. Su edad ósea era de 11 años. En la ecografía el útero medía $4,1 \mathrm{~cm}$ de largo y sus diámetros (mayor y menor) 2,3 y $0,5 \mathrm{~cm}$ respectivamente; los anexos no fueron vistos. En el cariograma de linfocitos se ençontró $88 \%$ de mitosis $45 \mathrm{XO}, 10 \%$ $46 / \mathrm{XrX}+2 \%$ 47XrXrXr (Figura 3). Dieciocho meses después había crecido $5,5 \mathrm{~cm}$ de estatura, tenía escaso vello pubiano y se esperaba que alcanzara su máximo crecimiento espontáneo para iniciar sustitución hormonal con estrógenos.

\section{COMENT ARIO}

La varjante isocromosona $X$ para el brazo $q$ (monosomia para el brazo p), tiene una frecuen. 
cia aproximada de $15 \%$ entre las disgenesis gonadales femeninas, en cambio la del cromosoma en anillo no sobrepasa el $2 \%^{4-7}$ En 19 anos hemos reunido 108 casos de disgenesias gonadales tipo Turner, 19 fueron causadas por iso $\mathrm{Xq}$ y sola. mente uno por anillo, en concordancia con las referencias citadas. Las mujeres con cromatinanegativas aparecen con una frecuencia de $1 \mathrm{x}$ 4.000 nacimientos, pero es dificil calcular su proporción exacta, pues en las descripciones no se incluyen mosa icos ni alteraciones estructurales. Más difícil aún es sospechar el número de zigotos que presentan la alteración, ya que aproximadamente un $95 \%$ sufre abortos espontáneos. Las manifestaciones clínicas de las variantes disgenéticas producidas por alteraciones estructurales pueden diferir del patrón clásico (Tabla 1). En nuestro caso de isocromosoma $\mathrm{Xq}$ la cromatina de Barr fue positiva, apoyando la idea de que este examen de rastreo no permite su detección; aún más el recuento puede resultar alto por aumento de tamaño del corpúsculo, lo que hace más fácil detectarlo y, además, algunas células tienen varios corpúsculos, pues existe más de una cromatina patológica; los síntomas de talla baja y disgenesia gonadal están generalmente presentes en estos casos. La situación causada por el cromosoma $X$ en anillo también es diferente: los pacientes son a su vez cromatina-positivos; pero su estatura puede no estar comprometida y las características sexuales secundarias pueden ser normales. De acuerdo a los postulados de Lyon y $\mathrm{Hoo}^{2,3}$, el isocromosoma $\mathrm{Xq}$ carece de genes que determinan normalidad gonadal, en cambio enel $X$ en anillo los genes perdidos pueden ser mínimos. La aparición del mosaico, vale decjr con distintas líneas cromosómicas, probable. mente sería postcigota, debida a pérdida, en algunas células, del cromosoma normal. Asi se explica que algo menos de la mitad de los casos descritos con cromosoma en anillo tengan menstruación, pudiendo postularse un período de fertilidad, que sería de corta duración ${ }^{9,10,11}$. La jởea de Ferguson Smith ${ }^{8}$, según la cual las anomalías del sindrome de Turner se producirian por la monosomía para el brazo p del cromosoma $X$, concuerda con nuestro caso del isocromosoma. Ni ella ni la segunda paciente tendrán de. sarrollo sexual debjdo a ta disgenesia gonadal. En la actualidad se estima que es fundamental el tratamiento psicológico, que debe comenzar cuando las pacientes son pequeñas; además se le explicará a los padres las causas y efectos de la alteración cromosómica; un ambiente favorable se traduce en una buena adaptación social. El tratamiento hormonal sustitutivo se hará en el momento de detención del crecimiento lineal, no usándose ya los anabólicos. Las expectativas de
Tabla 1 .

Síntomas clínicos de nuestros casos en relación a los clásicos del síndrome de Turner

\begin{tabular}{|c|c|c|c|}
\hline Síntoma & $\underset{\%}{\text { Turner }}$ & $\begin{array}{c}\text { Mosaico } \\
\text { isoXq } \\
\text { (Pte 1.) }\end{array}$ & $\begin{array}{c}\text { Mosaico } \\
\text { IX } \\
\text { (Pte 2) }\end{array}$ \\
\hline Retardo mental & 8 & \pm & - \\
\hline Baja estatura & 100 & + & + \\
\hline $\begin{array}{l}\text { Pecho en } \\
\text { escudo }\end{array}$ & 80 & + & + \\
\hline $\begin{array}{l}\text { Mamilas } \\
\text { separadas }\end{array}$ & 80 & + & + \\
\hline Cardiopatía & 26 & + & - \\
\hline Cuello alado & 54 & + & - \\
\hline $\begin{array}{l}\text { Cúbito valgo } \\
\text { IV metacarpiano }\end{array}$ & 70 & + & + \\
\hline cor to & 58 & - & + \\
\hline Linfoedema & 39 & - & - \\
\hline Lunares & 52 & + & - \\
\hline $\begin{array}{l}\text { Menstruación } \\
\text { Disgenesja }\end{array}$ & 5 & - & - \\
\hline gonadal & 95 & + & + \\
\hline $\begin{array}{l}\text { Edad materna } \\
\text { (años) }\end{array}$ & 28 & 35 & 23 \\
\hline $\begin{array}{l}\text { Edad paterina } \\
\text { (arios) }\end{array}$ & 32 & 37 & 33 \\
\hline
\end{tabular}

vida para estos pacientes son normales $y$ las complicaciones escasas. Es posible que en futuro cercano sea posible realizar trasplantes ováricos.

\section{RESUMEN}

Se describen dos pacientes con disgenesia gonadal femenina con cromatina positiva: un caso de isocromosoma $\mathrm{Xq}$ y otro con cromosoma $X$ en anillo. Se comparan los hallazgos clínicos con los del síndrome de Turner clásico y se comenta las posibilidades de fertilidad en los casos que tienẹn cromosoma en anillo.

\section{REFERENCIAS}

1. Lyon, M.F.: Attemps to test the inactive $\mathrm{X}$. Theory of compensation in mammals. Genet. Res. 4: 93, 1963.

2. Lyon, M.F.: Evolution of $\mathrm{X}$ chromosome inactiva tion in mammals. Nature 250: 651, 1974.

3. Hoo, $J_{1} J_{1}:$ Cytogenetic evidence for evolution of $\mathrm{X}$ chromosome inactivation. Lancet 1: 1299, 1975.

4. Reindollar, R. Rogers, J., Mc Donough. P.G.: Delayed sexual development. A study of 252 patjents. Delayed Ginecol. 141: 371, 1981.

5. Mc Donough, P.G.: Amenorrhea. Etiologic approach to diagnosis. Fertility and Sterility. 30:1, 1978.

6. Gardner, LI.: Endocrine and genetic diseases of chilhood and adolescence. 2nd ed. Saunders Co. 1975. Philadelphì, pág. 795 -796. 
7. Aspilloga, M., Morizon, G.: Disgenesia gonadal Cuadto clínico citogenética y dermatoglifico. Rev. Chil. Pediatr. 39; 265, 1968.

8. Ferguson Smith. M.A.: Karyotype phenotype correlation in gonada1 dysgenesis and their bearing on the pahtogenesis of malformation. J. Med. Genet. 2: 93, 1965.

9. Neu, R.L., Kofii, T., Voorhess, M.L., Gardnet, L.A.
Triple mosaicism in a phenotypic female. J. Pediatr. 74 : $794,1969$.

10. Wiss, D., De Lazier, C.D., Doniel, J., Engel, E.: Structural anomalies of the $\mathrm{X}$ chromosome. Clin. Genet. 21: 145, 1982.

11. Fitzgerald, P.H., Donald, R.A., Mc Cormick, P.: Reduced fertility in wooman with $\mathrm{X}$ chromosome abnormality. Clin. Genet. 25: 301, 1984. 